\title{
Call for Europe-wide nuclear physics push
}

[MUNICH] Nuclear physicists in Europe must collaborate more closely to answer the next big questions in their fields, according to experts from 23 research organizations.

A new report published by the Nuclear Physics European Collaboration Committee (NuPECC), an advisory body to the European Science Foundation, says it is important to draw together Europe's somewhat disparate nuclear physics community because the subject has reached a point at which large and expensive equipment is required to take it further.

One of the report's main recommendations is that the options for a second-generation radioactive ion beam in Europe should be defined as soon as possible. Such a beam would be able to create heavier ions, rich in neutrons, than has so far been possible. It would also allow the structure and characteristics of heavy ions to be determined, thus providing a better understanding of the first milliseconds of the Universe during which thousands of different types of such ions are predicted to have existed.

Sydney Galès, chairman of NuPECC and director of the Institute of Nuclear Physics in Orsay, says that it is vital for Europe to move quickly in heavy-ion physics because, although it currently plays a leading role in this field, it could lose its competitive edge as the United States and Japan both implement plans to upgrade their equipment.

The technologies involved in the design of future radioactive heavy-ion beams, such as high-density accelerators or reactors, share characteristics with technologies being developed for other uses, such as transmutation techniques for disposing of nuclear waste, and next-generation neutron spallation sources.

As a result, NuPECC has set up an interdisciplinary study group to identify options. The group will report at the end of next year, and at that stage NuPECC will put out a call for funding to research agencies, says Galès.

The report also recommends that a highluminosity $25-\mathrm{GeV}$ electron beam facility be built in Europe soon, to further studies on the structure and dynamics of hadrons. All the major hadron experiments now being conducted in Europe will be completed in the next six or so years.

The scientific council of the German particle-physics research centre DESY agreed last autumn to consider using its planned high-energy TESLA linear collider to generate such an electron beam, which could inject electrons at the appropriate energy into its existing HERA electron storage ring.

This strategy would be considerably cheaper than building a $25-\mathrm{GeV}$ electron facility from scratch. DESY has asked NuPECC to provide a clear physics case for the idea, and to define a clear user community and costing within the next two years.

NuPECC's report is the second of a planned series of six-yearly surveys. According to Galès, three-quarters of the recommendations of the last report, published in 1991, were put into practice. He hopes that the current report will be equally well received by funding agencies, although admitting that "the political climate has changed in the last few years".

Some of the report's recommendations are already being implemented. For example, the European particle-physics laboratory CERN has approved a heavy-ion experiment called Alice (A Large Ion Collider Experiment) to run on its Large Hadron Collider, which comes into operation in 2005. This will help to answer questions about properties of quarks and gluons, the building blocks of nuclear particles.

Alison Abbott

\section{French research agency to seek ruling on Holocaust sceptics}

[PARIS] France's national scientific research agency is to try to clarify a course of action on researchers who actively promote 'revisionist' arguments such as denying the existence of the Nazi gas chambers.

The Centre Nationale de la Recherche Scientifique (CNRS), which is split between the need to preserve academic freedom and a desire to discipline such individuals, will ask its ethics committee, COMETS, for advice, on which the agency's national committee will then act.

The question of revisionism in French academic circles has been kept simmering for some time by the revisionist activities of Serge Thion, a CNRS researcher, as well as those of several other scientists.

The issues are particularly sensitive given that France has recently been reminded of Fascist activities in its past by the trial of Maurice Papon - a senior civil servant imprisoned for collaboration in Nazi deportations - and the significant role of the National Front in recent regional elections.

Matters were brought to the boil in February by allegations in the German newspaper Berliner Zeitung, attributing revisionist arguments - in particular that the existence of the Nazi gas chambers had not been proved - to Gabor Rittersporn, a CNRS researcher working at the prestigious Marc-Bloch Franco-German
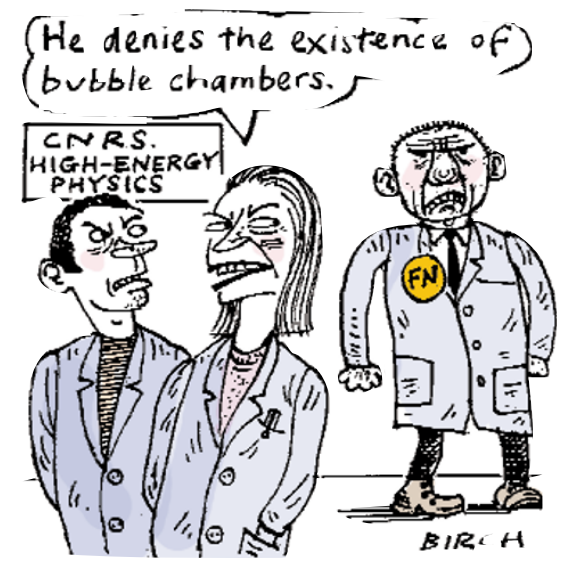

centre for social sciences in Berlin.

Earlier this month, the researcher won a court case against the newspaper and cleared his name. Rittersporn, who was born in Hungary, had denied the allegations and condemned revisionism, telling the court that some members of his family, itself partJewish, had perished in the Holocaust.

The allegations against Rittersporn followed revelations about his membership in the 1970s and 1980s of extreme left-wing groups that favoured free expression for revisionists. He was also a member of the editorial board of La Vieille Taupe, a French publisher that has published revisionist texts, including one on the gas chambers which Thion edited.

But Rittersporn has argued that he was at the time naively defending freedom of expression, and ceased participating in these activities when he learnt they were being used to support revisionism. Etienne François, the director of the Marc-Bloch institute, said at the time that Rittersporn's past activities had been fully discussed at CNRS before his appointment, and that the agency had been satisfied by Rittersporn's explanations.

In response to the highly publicized controversy generated by the Rittersporn case, CNRS set up an expert panel chaired by Edouard Brezin, president of its executive board, to consider the issue of revisionism among academics. But Brezin says he quickly realized that such a panel had few powers to investigate the behaviour of individual researchers.

Given this lack of power, and that the urgency has dissipated with the intervening court ruling clearing Rittersporn, CNRS has decided to dissolve the panel and pass the issue to COMETS for guidance. It will then ask the CNRS's national committee, which has the power to evaluate researchers, to take appropriate action.

Brezin says he hopes COMETS will clarify the limits of academic and individual freedom for public researchers, as well as CNRS's disciplinary powers. Declan Butler 